\title{
Quality of life in elderly Portuguese war veterans with post-traumatic stress symptoms
}

This article was published in the following Dove Press journal: Patient Related Outcome Measures

\author{
M Graça Pereira' \\ José C Machado² \\ Marta Pereira' \\ Cristiana Lopes ${ }^{3}$ \\ Susana Pedras' \\ 'School of Psychology, University \\ of Minho, Braga 47 I0-057, Portugal; \\ ${ }^{2}$ Institute of Social Sciences, \\ University of Minho, Braga 4710-057, \\ Portugal; ${ }^{3} \mathrm{Hospital}$ of Braga, Sete \\ Fontes - São Victor Braga 47। 0-243, \\ Portugal
}

Background: Studies show that post-traumatic stress symptoms among Portuguese veterans who participated in Colonial War (1961-75) are high, even though 43 years have gone by since the end of the war.

Aims: This study analyzed the role of family type, personality traits, and social support as predictors of post-traumatic stress symptoms and quality of life in war veterans, and whether satisfaction with social support was a mediator between neuroticism/post-traumatic stress symptoms and quality of life.

Method: A cross-sectional study was conducted including 230 war veterans with a mean age of 60 years $(\mathrm{SD}=3.82)$.

Results: Results indicated a high prevalence of post-traumatic stress symptoms as well as high neuroticism, 16.5 ( $\mathrm{SD}=4.41)$; 81\% of veterans presented high psychological distress, suggesting emotional disturbance and $71 \%$ belonged to extreme families (families with cohesion and adaptability problems). Results showed that age $(\beta=-0.166, p<0.05)$, social support $(\beta=-0.184$, $p<0.01)$, and neuroticism $(\beta=0.325, p<0.001)$ predicted post-traumatic stress symptoms. Age, professional status, social support, post-traumatic stress symptoms, family type, neuroticism, and extroversion predicted different dimensions of quality of life. Finally, a path analysis showed that satisfaction with social support was a mediator in the relationship between neuroticism and quality of life $(\beta=-0.066 ; p<0.01)$ and between post-traumatic stress symptoms and quality of life $(\beta=-0.108 ; p<0.01)$.

Conclusion: Four decades after the Colonial War have passed, there is still a high prevalence of post-traumatic stress symptoms. Screening elderly veterans who present post-traumatic stress symptoms, for the presence of neuroticism traits, and assessing family type and social support, should be a standard practice in health care services, especially in the oldest and those who are retired. Social support should be promoted in order to enhance quality of life in this population. Keywords: war veterans, post-traumatic stress symptoms, personality traits, social support, quality of life

\section{Introduction}

In Portugal, about 1 million young Portuguese went to mandatory military service in Africa (Guinea, Angola, and Mozambique) between 1961 and 1975, corresponding to $10 \%$ of the country's population in what was called the Colonial War. In an epidemiological study conducted by Albuquerque, ${ }^{1}$ in 1992, it was estimated that 140,000 of those who served their country and returned had severe chronic psychological problems. However, the psychological problems in this population are "hidden in plain sights" and it is important to offer the appropriated physical and mental health services.
Correspondence: M Graça Pereira School of Psychology, University of Minho, Campus de Gualtar, Braga 47I0-057, Portugal

Tel +35I 253604683

Email gracep@psi.uminho.pt 
In fact, there are some studies that revealed high rates of post-traumatic stress symptoms in Portuguese war veterans. Maia et $\mathrm{al}^{2}{ }^{2}$ in a sample of 350 veterans, found a prevalence of $56 \%$ of veterans with psychological distress related to post-traumatic stress symptoms, and 39\% fulfilled the criteria for a post-traumatic stress disorder (PTSD) diagnosis. Pedras and Pereira, ${ }^{3}$ in a sample of 101 veterans, found that $71 \%$ showed high levels of psychological distress, and $45 \%$ fullfilled the criteria for a PTSD diagnosis.

Personality traits are responsible for a stable structure of personality ${ }^{4}$ and have been linked to post-traumatic stress symptoms and PTSD, in war veterans. ${ }^{5}$ According to Roberts et al, ${ }^{5}$ personality traits such as low neuroticism and high extroversion have been associated with better health, and neuroticism has been referred to as an important predictor of PTSD in war veterans. Veterans without PTSD, on the other hand, have shown lower neuroticism compared to those with PTSD. ${ }^{6}$

The Family Circumplex Model is built on the principles of family systems theory, which emphasizes the interconnectedness of family members and their behaviors, ${ }^{7}$ comprising two dimensions of family behavior: cohesion and adaptability. Cohesion refers to the emotional bonding, or closeness, among family members and the adaptability refers to the amount of change in family leadership, roles and rules. Optimal functioning involves a balance of stability and change. According to the Circumplex Model, a balanced family operates more gently than unbalanced family systems. Extreme families are those that are unbalanced in both dimensions of cohesion and adaptability. Therefore, PTSD has a negative impact on the cohesion and adaptability of family functioning, and may, in fact, differentiate veterans with and without PTSD. Findings revealed associations between PTSD symptom severity and high levels of conflict, more family and dyadic stress, poor cohesion and adaptability, and poor communication skills, suggesting that the presence of PTSD symptoms may have important implications in family life. ${ }^{8-10}$

Social support is a protective factor after exposure to trauma and works as a stress-buffer. ${ }^{11}$ The lack of social support is related to the development of PTSD in war veterans, with the increase of the number and intensity of PTSD symptoms, with the development of anxiety and depression symptoms, and with the consumption of alcohol. ${ }^{12}$ Therefore, social support is a valuable resource that should be promoted in this population.

As a result of experiencing post-traumatic stress symptoms and psychological distress, along with certain personality traits and characteristics of family functioning, the quality of life (QoL) of war veterans has been considered substantially poor. In a study with veterans from former Yugoslavia, 83.7\% showed PTSD and lower QoL, assessed with the Clinician Administered PTSD Scale (CAPS) and the Manchester Short Assessment of Quality of Life (MANSA). ${ }^{13}$ Chronic PTSD in Vietnam veterans (first assessed in 1984 and followed-up 14 years later) has also been associated with a low global QoL, poor psychosocial adjustment, less satisfaction with life and happiness, worse family relationships, more smoking, more use of mental health services, and nonspecific health complaints. ${ }^{14}$ In addition, war veterans show poor physical health and deficits in social functioning. ${ }^{13-15}$ PTSD is the anxiety disorder with the most negative impact on QoL (measured by the Quality of Life Enjoyment and Satisfaction Questionnaire) ${ }^{16}$ and one of the major predictors of QoL, in individuals with PTSD (measured through the CAPS) has been the intensity of their symptoms. ${ }^{16}$ However, other potential modulating variables between PTSD and QoL should be examined.

According to the literature, neuroticism is a risk factor for QoL. Similarly, Steel et al ${ }^{17}$ found that neuroticism was a negative predictor of satisfaction of life and, indirectly, of QoL. According to Lahey, ${ }^{18}$ individuals with high neuroticism often evaluate events and situations in a negative perspective, are more responsive to negative feedback, more likely to overestimate the difficulties they face, and show a cognitive and behavioral rumination style regarding negative experiences and frustrations. Also, social support acts as a protective factor against the deleterious effects of neuroticism ${ }^{19}$ and Panayiotou and Karekla ${ }^{20}$ found perceived social support to have a direct and positive effect on QoL. Therefore, one may hypothesize that social support may have a mediating role between posttraumatic stress symptoms/ neuroticism and QoL.

Although PTSD symptoms improve with age, retirement tends to worsen PTSD symptoms ${ }^{21}$ not only due to the natural process of aging and physical illness but also due to the loss of friends, the decline in economic resources and the common somatic complaints due to the disease, in individuals with PTSD. ${ }^{22}$ Thus, it is important to be aware of the increased prevalence of PTSD in the elderly war veterans and the need to adapt interventions not only to PTSD symptoms in the war veterans' population but also to the aging process (ie, cognitive decline, physical complaints). ${ }^{23}$

Therefore, the purpose of this study was: 1) to find the best predictors of post-traumatic stress symptoms and 2) to find the best predictors of QoL, in a sample of Portuguese 
elderly war veterans. Specifically, this study explored whether personality traits and family type predicted post-traumatic stress symptoms and analyzed whether social support was a mediator between post-traumatic stress symptoms and QoL as well as between neuroticism and QoL. Most studies with war veterans that address the relationship between personality traits, social support, and QoL were done with younger veterans. ${ }^{24}$ It was hypothesized that contextual variables such as social support, family functioning, and personality traits together with post-traumatic stress symptoms, personality traits, and demographic variables, will impact QoL. From a heuristic point of view such information would be beneficial, for intervention, and to guide future studies evaluating interventions in trauma populations.

\section{Material and methods Participants}

The total sample included 230 male veterans. The mean age of the veterans was $60(\mathrm{SD}=3.82)$ and ranged from 51 to 73 years. Of the total sample, $78 \%$ had only four years of education, $91 \%$ were married, $21 \%$ were employed, $16 \%$ were unemployed, $64 \%$ were already retired in which $7 \%$ due to disability and, finally, $7 \%$ were on sick leave. In terms of war theater, veterans served in Angola (43\%), Guinea (29\%), Mozambique (27\%), and India (1\%). Most of the veterans were soldiers (88\%) and served in the Army (94\%). Only $6 \%$ of veterans had served as special troops (Marines and Rangers).

\section{Procedure}

Veterans were recruited from the Psychiatry Departments of a Central Hospital and a Veterans Organization, in the north of Portugal. Participants were sent by their family physician to these institutions due to the high prevalence of patients' posttraumatic stress symptoms. Of the total sample, $60 \%$ were recruited from the Veterans Organization and the remaining from the hospital. The total sample included 250 outpatient war veterans who were invited to participate in the study, but only 230 accepted.

The assessment was made by a psychologist and a psychiatrist through a psychological evaluation protocol. Veterans that did not accept to participate did not differ from participants in clinical and sociodemographic variables. Participants who accepted to participate in the study signed a written informed consent and the participation was voluntary. A quantitative and cross-sectional design was used. The study was approved by the review board from of both the Psychiatry Department of a Central Hospital in the north of Portugal (Braga Hospital Center) and the Veterans Organization (Portuguese
Association of War Veterans-APVG). This study was carried out on in compliance with the Helsinki Declaration.

\section{Measures}

The Portuguese version of the following instruments was used:

\section{Post-traumatic Stress Scale (PTSS)}

This instrument has 17 items (yes/no) addressing post-traumatic stress symptoms, regarding a traumatic experience. PTSS is divided into three subscales according to the DSM-IV criteria: re-experiencing the event-this subscale assesses intrusion symptoms (five items); avoidance - this subscale assesses denial and numbness symptoms (seven items); and finally arousal - this subscale assesses hypervigilance and activation symptoms (five items). Veterans were instructed to answer PTSS regarding their war experience. The total score ranges from 0 to 17 symptoms. A high result indicates more post-traumatic stress symptoms. Cronbach alpha in this sample was $0.79 .{ }^{25}$

\section{Brief Symptom Inventory (BSI)}

This instrument assesses psychological distress and comprises 53 items rated on a 5-point Likert scale and nine subscales: somatization, depression, anxiety, phobic anxiety, hostility, psychoticism, paranoid ideation, interpersonal sensibility, and compulsive obsession. The instrument also provides a Global Severity Index (GSI). The cutoff score for the Portuguese population is 1.7 , indicating clinical emotional disturbance. A high result indicates more psychological distress. Cronbach's alpha in this sample for all subscales ranged from 0.70 to $0.80 .^{26}$

\section{Family Adaptability and Cohesion Evaluation Scales III (FACES III)}

FACES III assesses family functioning. The instrument comprises 20 items rated on a 5-point Likert scale allowing to distinguish three family categories: balanced, midrange, and extreme. In extreme families, there are problems in cohesion and adaptability (too low or to high), in midrange families, the adaptability and cohesion levels are moderate, and in balanced family, there is a good adaptability to new situations and emotional closeness as well. Balanced levels of cohesion and adaptability reflect more healthy family functioning, while unbalanced levels of cohesion and adaptability reflect problematic family functioning. Cronbach's alpha, in this sample, was 0.82 for the cohesion scale and 0.87 for the adaptability scale. ${ }^{27}$ 


\section{Social Support Satisfaction Scale (SSSS)}

This scale assesses social support and comprises 15 items and 4 dimensions of satisfaction with social support: satisfaction with friends, satisfaction with family, satisfaction with social activities, and satisfaction with intimacy. Items are rated on a 5-point Likert scale. A higher result indicates high satisfaction with social support. In this study, only the total scale was used with a Cronbach's alpha of $0.87 .{ }^{28}$

\section{Eysenck Personality Inventory (EPI)}

This instrument assesses two dimensions of personality consisting of two dimensions: extroversion-introversion and neuroticism-stability. It comprises 57 dichotomous items (yes/ no) and consists of a validity scale for those who are prone to respond in a socially desirable way (lie scale). High extroversion scores indicate individuals who tend to be outgoing, impulsive, and uninhibited; have many social contacts; and often take part in-group activities; while lower scores usually characterize more passive, introspective, and reserved individuals (introversion). Individuals with a high score in neuroticism are prone to emotional distress/instability, while lower scores indicate calm and emotionally stable individuals (stability). The extroversion scale showed test-retest reliability of 0.89 and the neuroticism scale of 0.86 . In this sample, Cronbach's alpha for neuroticism was 0.84 , and 0.70 for extroversion. ${ }^{29}$

\section{WHOQOL-Brief}

This instrument assesses four dimensions of QoL: physical QoL (eg, activities of daily living) with seven items; social QoL (eg, social support) with three items; psychological QoL (eg, self-esteem) with six items; environmental QoL (eg, financial resources) with eight items, and two other independent items that assess QoL and overall QoL and health in a 5-point Likert scale. A higher score indicates a high QoL in each dimension. Cronbach's alphas, in this sample, ranged between 0.64 and $0.87 .{ }^{30}$

\section{Data analysis}

The software IBM SPSS Statistics 22 and IBM SPSS, Amos, 22 were used for data analysis. Descriptive statistics were conducted to find the mean value of post-traumatic stress symptoms, neuroticism and extroversion traits, psychological distress, social support, and the four dimensions of QoL. Percentages were calculated to determine the family type rate and the presence of psychological distress according to GSI. Two hierarchical multiple regression analyses (method enter) were conducted. The first, to find the best predictors post-traumatic stress symptoms and the second, to find the best predictors of QoL. In the two regression models, age, war theater (Angola and Mozambique compared to Guinea), professional status (unemployment, retirement and being on sick compared to employment) were introduced in the first block. Psychological variables were included in the second block. The multicolinearity was tested and was not a problem (VIF <3). Finally, a path analysis was used to find whether social support was a mediator in the relationship between post-traumatic stress symptoms and neuroticism, both as independent variables and QoL as a dependent variable. For the refinement of the final model, the modification indices and the quality of the model fit was assessed with the indices $\mathrm{X}^{2} / \mathrm{df}$, comparative fit index (CFI), goodness of fit index (GFI), root mean square error of approximation (RMSEA) and $P$ (rmsea $\leq 0.05)$ and their respective reference values. Mediating effects indicated in the results section are standardized values.

\section{Results}

\section{Psychological characterization of the sample}

The mean value for post-traumatic stress symptoms was 12.2 $(\mathrm{SD}=4.69)$ out of 17 maximum possible, revealing a very high percentage of post-traumatic stress symptoms in this clinical sample as well as high neuroticism, $16.5(\mathrm{SD}=4.41)$ out of 21 maximum possible. A greater percentage of the sample (81\%) showed psychological distress, well above the norms, compared to the mean, in nonclinical samples, according to the GSI of the BSI ( $>1.7)$, indicating emotional disturbance. Most of the veterans $(71 \%)$ belonged to extreme families and only $29 \%$ belonged to midrange families. Table 1 shows the descriptive statistics.

\section{Variables that contribute to post- traumatic stress symptoms}

Younger age, less social support and neuroticism contributed more post-traumatic stress symptoms. The model explained $18 \%$ of the variance (Cohen's $f=0.276$ ). All the other variables did not contribute to post-traumatic stress symptoms (Table 2).

Table I Descriptive statistics

\begin{tabular}{|l|l|l|l|l|}
\hline & Minimum & Maximum & Mean & SD \\
\hline Neuroticism Traits & 0 & 21 & 16.47 & 4.41 \\
\hline Extroversion Traits & 0 & 26 & 8.87 & 3.38 \\
\hline $\begin{array}{l}\text { Post-traumatic Stress } \\
\text { Symptoms }\end{array}$ & 0 & 17 & 12.21 & 4.69 \\
\hline Social QoL & 3 & 14 & 8.44 & 1.88 \\
\hline Psychological QoL & 6 & 26 & 16.19 & 3.67 \\
\hline Physical QoL & 7 & 28 & 18.02 & 3.95 \\
\hline Environmental QoL & 9 & 32 & 20.08 & 4.09 \\
\hline Psychological Distress (GSI) & 0 & 4 & 2.32 & 0.73 \\
\hline Social Support & 15 & 75 & 46.35 & 0.575 \\
\hline
\end{tabular}

Abbreviations: GSI, Global Severity Index; QoL, Quality of Life. 


\section{Variables that contribute to QoL}

The results showed that older age, predicted higher psychological, social and environmental QoL. Being retired negatively predicted social QoL. Social support positively predicted physical, psychological, social and environmental QoL. Belonging to an extreme family negatively predicted social QoL. Post-traumatic stress symptoms negatively predicted physical, psychological, and environmental QoL. Neuroticism and extroversion traits predicted negatively and positively psychological QoL, respectively. The models

Table 2 Variables that contribute to post-traumatic stress symptoms (Final model)

\begin{tabular}{|l|l|l|l|}
\hline & B & SE & $\beta$ \\
\hline Block I & & & \\
\hline Age & -0.203 & 0.083 & $-0.166^{*}$ \\
\hline War theater Angola & -0.288 & 0.674 & 0.030 \\
\hline War theater Mozambique & -1.120 & 0.760 & -0.106 \\
\hline Unemployment & -1.428 & 0.966 & -0.113 \\
\hline Retirement & -0.503 & 0.815 & -0.054 \\
\hline Sick Leave & -0.758 & 0.998 & -0.055 \\
\hline Block 2 & & & \\
\hline Social support & -0.099 & 0.035 & $-0.184^{\text {** }}$ \\
\hline Extreme family & -0.261 & 0.635 & -0.025 \\
\hline Neuroticism & 0.345 & 0.070 & $0.325^{\text {*k+ }}$ \\
\hline Extroversion & -0.166 & 0.090 & 0.067 \\
\hline R-squared & & 0.216 & \\
\hline Adjusted R-squared & & 0.180 & \\
\hline Cohen's f & & 0.276 & \\
\hline
\end{tabular}

Notes: ${ }^{*}<<0.05 ; " p<0.01 ; " p<0.001$. for physical, psychological, social and environmental QoL explained $19 \%, 34 \%, 31 \%$ and $43.5 \%$ of the variance respectively (Cohen's $f=0.304 ; 0.590 ; 0.529$, and 0.435 , respectively) (Table 3).

\section{Satisfaction with social support as a mediator between post-traumatic stress symptoms/neuroticism and QoL}

The final mediation model showed a good fit: $\mathrm{X}^{2} / \mathrm{df}=2.586$ $(p>0.05) ; \mathrm{CFI}=0.989 ; \mathrm{GFI}=0.994 ; \mathrm{RMSEA}=0.083 ; P(\mathrm{rmsea}$ $\leq 0.05)=0.206$. The indirect effect of post-traumatic stress symptoms on QoL through social support $(\beta=-0.108 ; p<0.01)$ and the indirect effect of neuroticism on QoL through social support were significant $(\beta=-0.066 ; p<0.01)$. In the first case, since there was also a direct effect, the mediation was partial and in the second situation was total (Figure 1).

\section{Discussion}

In this sample, veterans presented a high number of posttraumatic stress symptoms. In fact, $81 \%$ of veterans presented psychological distress and $42 \%$ presented simultaneously a diagnosis of PTSD and emotional disturbance, based on the cutoff point of the BSI-GSI. The literature shows psychological distress (eg, mood disorders) as the most common comorbidity in war veterans with PTSD $^{2,31}$ and that PTSD and emotional disturbance together, are associated with more distress, the utilization of mental health services and

Table 3 Variables that contribute to quality of life

\begin{tabular}{|c|c|c|c|c|c|c|c|c|c|c|c|c|}
\hline & \multicolumn{3}{|c|}{ Physical QoL } & \multicolumn{3}{|c|}{ Psychological QoL } & \multicolumn{3}{|c|}{ Social QoL } & \multicolumn{3}{|c|}{ Environment QoL } \\
\hline & B & SE & $\beta$ & B & SE & $\beta$ & B & SE & $\beta$ & B & SE & $\beta$ \\
\hline \multicolumn{13}{|l|}{ Block I } \\
\hline Age & 0.016 & 0.071 & 0.016 & 0.148 & 0.060 & $0.154^{*}$ & 0.089 & 0.031 & $0.180^{*}$ & 0.179 & 0.070 & $0.167^{*}$ \\
\hline War theater Angola & 0.137 & 0.568 & 0.017 & 0.002 & 0.478 & 0.000 & -0.357 & 0.250 & -0.094 & -0.283 & 0.561 & -0.034 \\
\hline $\begin{array}{l}\text { War theater } \\
\text { Mozambique }\end{array}$ & 0.565 & 0.645 & 0.063 & -0.095 & 0.543 & -0.011 & -0.163 & 0.284 & -0.038 & 0.087 & 0.637 & 0.009 \\
\hline Unemployment & -1.272 & 0.824 & -0.120 & 0.542 & 0.694 & 0.055 & -0.100 & 0.362 & -0.020 & -0.216 & 0.814 & -0.020 \\
\hline Retirement & -1.282 & 0.696 & -0.162 & -0.373 & 0.568 & -0.051 & -0.763 & 0.306 & $-0.202^{*}$ & -0.766 & 0.688 & -0.093 \\
\hline Sick leave & -0.963 & 0.849 & -0.083 & 0.430 & 0.714 & 0.040 & -0.263 & 0.373 & -0.048 & -0.159 & 0.838 & -0.013 \\
\hline \multicolumn{13}{|l|}{ Block 2} \\
\hline Social support & 0.080 & 0.031 & $0.177^{* *}$ & 0.122 & 0.026 & $0.289^{\text {k*kk }}$ & 0.078 & 0.014 & $0.363^{\text {*tok }}$ & 0.141 & 0.030 & $0.300^{* * * *}$ \\
\hline Extreme family & -0.944 & 0.539 & -0.108 & 0.307 & 0.454 & 0.038 & 0.479 & 0.237 & $0.115^{*}$ & 0.154 & 0.533 & 0.017 \\
\hline $\begin{array}{l}\text { Post-traumatic } \\
\text { stress symptoms }\end{array}$ & -0.214 & 0.058 & $-0.253^{\text {*ak }}$ & -0.113 & 0.049 & $-0.144^{*}$ & -0.038 & 0.026 & -0.094 & -0.193 & 0.058 & $-0.220^{\text {sisk }}$ \\
\hline Neuroticism & -0.001 & 0.067 & -0.001 & -0.115 & 0.057 & $-0.134^{*}$ & -0.043 & 0.030 & -0.097 & -0.039 & 0.066 & -0.041 \\
\hline Extroversion & 0.067 & 0.080 & 0.056 & 0.165 & 0.068 & $0.149^{*}$ & 0.028 & 0.035 & 0.049 & 0.004 & 0.079 & 0.003 \\
\hline R-squared & & 0.233 & & & 0.371 & & & 0.346 & & & 0.303 & \\
\hline Adjusted R-squared & & 0.190 & & & 0.336 & & & 0.309 & & & 0.264 & \\
\hline Cohen's $f^{2}$ & & 0.304 & & & 0.590 & & & 0.529 & & & 0.435 & \\
\hline
\end{tabular}

Note: $*_{p}<.05 ; * * p<.01 ; * * * p<.001$.

Abbreviation: QoL, quality of life. 


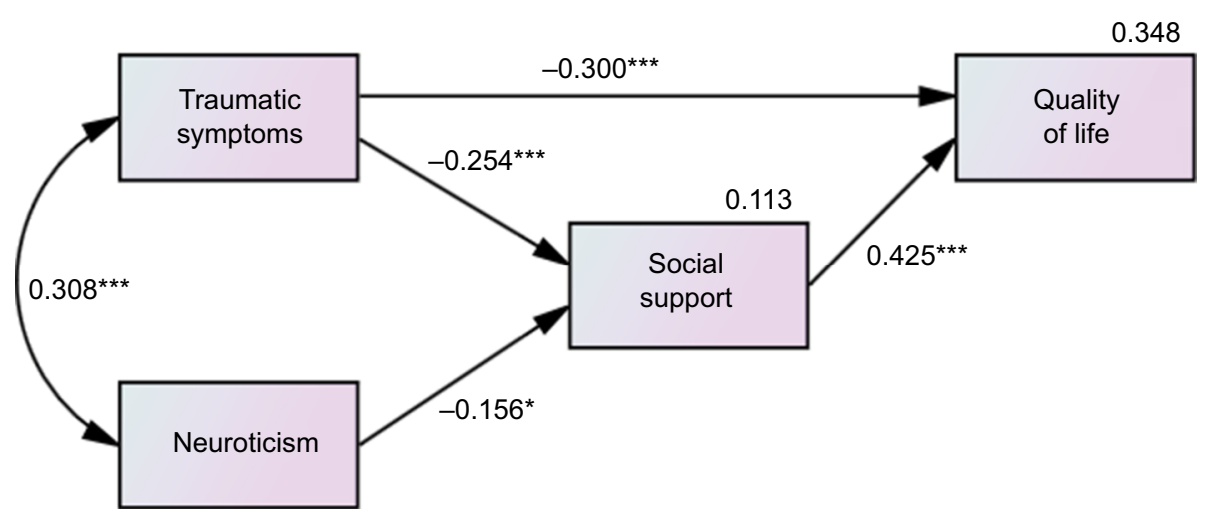

Figure I Path analysis (Standardized coefficients).

Notes: Model fit summary: $\mathrm{X}^{2} / \mathrm{df}=2.586 ; p=0.108 ; \mathrm{CFI}=0.989$; $\mathrm{GFI}=0.994 ; \mathrm{RMSEA}=0.083 ; p(\mathrm{rmsea}<0.05)=0.206$. Bootstrap results (standardized coefficient [95\% $\mathrm{Cl}$, probability): (I) indirect effect of PTSD Symptoms on QoL through the SSSS Global: -0.108 [ $-0.162 ;-0.072]$, $p=0.004 ;(2)$ indirect effect of EPI Neuroticism on QoL through the Social Support (SSSS Global): $-0.066[-0.118 ;-0.037], p=0.004$. $* p<0.05 ; * * * p<0.001$.

substance abuse. ${ }^{32}$ The results of the present study are in accordance with other studies that have found similar results in other countries. ${ }^{33}$ However, the variety of methodologies and instruments to assess post-traumatic stress symptoms, and the differences in sample size do not allow for the comparison between the mean value of post-traumatic stress symptoms in this study and other international studies. However, after so many years, a substantial percentage of veterans presented post-traumatic stress symptoms and, this fact, is worthy of attention by health professionals in clinical practice. The literature indicates that there are factors before, during and post-combat that are considered critical mediators in the expression of PTSD, such as intensity and duration of combat, personal vulnerability, other war zone experiences and a sociocultural and situational factors. The interaction of these risk factors may influence the development and adaptation of symptoms and significantly affect the prevalence and course of PTSD. ${ }^{34,35}$ Future studies should also integrate these potential mediating variables.

Younger age, perceiving less satisfaction with social support and having neuroticism traits predicted posttraumatic stress symptoms. Although the regression model only explained $18 \%$ of the variance, the Cohen's $f$ indicated a solid medium effect size (above $13 \%$ of variance is considered a medium effect size). Magruder et $\mathrm{al}^{36}$ found that post-traumatic stress symptoms were significantly related to age, ie, younger veterans showed more severe symptoms. In this study with older veterans, younger age played a similar role. In older veterans, avoidance and re-experiencing of the war situation may be less prominent features of PTSD than in younger veterans. Over time, trauma may no longer be such an important issue, and memories of these events may have faded. In addition, the autobiographical memory studies report that over time, negative events are remembered with less specificity and are less likely to evoke negative emotions. ${ }^{37}$ Other studies found that oldest older individuals tend to present more post-traumatic symptoms associated, especially, with the expected losses of the aging process. ${ }^{21-23}$ Neuroticism contributed to post-traumatic stress symptoms. The literature has shown that neuroticism has been involved in the development of PTSD in war veterans. ${ }^{38,39}$ People with traits of neuroticism tend to feel the world as threatening and harrowing, often seek less social support and ventilate less of their personal experiences, especially negative ones. ${ }^{40,41}$ They are typically more anxious and vulnerable to stress, presenting a lack of self-confidence, ${ }^{42}$ which may maintain the post-traumatic stress symptoms. A longitudinal study showed that individuals with higher levels of neuroticism, assessed in two different moments (young adults and in midlife), reported more intense physiological reactions to their memories of trauma, experienced more frequent involuntary memories of their traumas, and realized that the trauma was more central to one's identity, causing a greater intensity to the PTSD symptoms. ${ }^{41}$ Thus, according to the autobiographical memory theory, previously mentioned, individuals with greater neuroticism traits and negative affectivity present a higher risk of PTSD symptoms, partly as a result higher levels of cognitive-affective mechanisms that increase accessibility to their memories of trauma. ${ }^{41}$ Also, a meta-analysis of 77 studies indicated that, among several risk factors related to PTSD, lack of social support was the stronger predictor of PTSD, being related to severity of posttraumatic stress symptoms. ${ }^{43}$ Schnurr et al ${ }^{12}$ suggested that the lack of social support predicted both the development and the maintenance of PTSD. However, the relationship between post-traumatic stress symptoms and social support is bidirectional since trauma victims, due to symptoms of avoidance and emotional numbing, also tend to isolate 
themselves from their social support network. ${ }^{44}$ These results may be useful to health professionals in order to identify those veterans with post-traumatic stress symptoms and provide the psychological support they need, as well as to inform the design of psychosocial and community interventions, focused on promoting social support in younger colonial war veterans with more traits of neuroticism. In the literature, psychological intervention has been shown to be efficient in reducing post-traumatic stress symptoms. ${ }^{45-47}$ Although there is a wide variety of available psychotherapies, cognitive-behavioral therapy continues to gather greater consensus and evidence in reducing post-traumatic stress symptoms. Within these therapies, cognitive processing therapy $(\mathrm{CPT})^{48}$ and prolonged exposure therapy $(\mathrm{PE})^{49}$ are the most recommended for the treatment of PTSD symptoms and depression. ${ }^{49-53}$ However, there are also other psychotherapies in the treatment of PTSD symptoms that have reported good outcomes such as: behavioral activation ${ }^{54}$; eye movement desensitization and reprocessing (EMDR); ${ }^{55}$ interpersonal therapy ${ }^{56,57}$; and, last but not least, third generation therapies: acceptance and commitment therapy (ACT),${ }^{58}$ dialectical behavioral therapy (DBT),${ }^{59-61}$ and mindfulness. ${ }^{62,63}$

Another goal of this study was to find the predictors of QoL in war veterans. Age, social support, belonging to an extreme family, and extroversion were positive predictors and post-traumatic stress symptoms, neuroticism and being retired were negative predictors. Older age was a positive predictor of social, psychological, and environmental QoL, but not physical QoL. This result is understandable since with age, physical QoL decreases, but the impact of age on other dimensions of QoL should be better explored. As veterans grow old, the emotional maturity and coping strategies may help veterans gain a better psychological, social, and environmental QoL. ${ }^{64,65}$ Being retired was a negative predictor of social QoL. This study did not explore the socioeconomic status, but Portugal is among the countries with the lowest pensions in Europe ${ }^{66}$ and, as a result, less financial resources may have an impact on social QoL. In turn, social support predicted all dimensions of QoL. In fact, veterans with high levels of empathic, informative, and reassuring social support reported better QoL (eg, perceived QoL) than did those with lower levels of social support. ${ }^{65}$ Social support is undoubtedly an important positive and protective factor against stressful events and a promoter of QoL. ${ }^{11}$ Post-traumatic stress symptoms were a negative predictor of physical, psychological, and environmental QoL, as expected, highlighting their negative impact on QoL. However, post-traumatic stress symptoms did not predict social QoL. Social isolation might be a consequence of post-traumatic stress symptoms as well as a reaction to the traumatic symptoms (particularly symptoms of avoidance and hyperarousal) jeopardizing meaningful interpersonal relationships. We believe that post-traumatic stress symptoms did not predict social QoL since Portuguese veterans have several periodic social meetings, that are organized by local veterans' organizations and church, where they all get together and socially interact, highlighting the important social role of community resources. However, future research should pursue this hypothesis.

Interestingly, in this sample, the majority of veterans $(71 \%)$ belonged to extreme families, which in turn predicted a better social QoL. In extreme families, there are problems in cohesion and adaptability, reflecting more problematic family functioning since both extremes in which either too much or too little change on the adaptability dimension or too much or too little closeness on the cohesion dimension are considered problematic, indicating a low level of family functioning. Since satisfaction with social support plays an important role as a stress-buffer against familiar stress and conflicts $^{10}$ and partially mediates the relationship between post-traumatic stress symptoms and QoL according to the path analysis model, one might hypothesize that belonging to an extreme family may be associated with seeking social support and, as a consequence, with better social QoL. This result highlights, once again, the role of social support from friends and neighbors in war veterans' QoL, as well as the community at large, such as church groups and veterans' associations, especially in religious cultural contexts, such as Portugal.

In turn, neuroticism and extroversion traits predicted negatively and positively QoL, respectively. In fact, neuroticism is considered a risk factor for QoL, and low neuroticism and high extroversion have been associated with a better health. ${ }^{5}$ This result is expected if we consider that a premorbid personality characterized by high negative emotional/neuroticism combined with low positive emotionality predisposes the individual exposed to trauma to an internalized posttraumatic response expressed by marked social avoidance, anxiety, and depression. Similarly, a high neuroticism trait combined with low restriction/inhibition may predict an externalized post-traumatic reaction characterized by marked impulsiveness, aggression and a propensity for antisocialism and substance abuse. ${ }^{67}$ Extroversion trait has been also found to positively predict QoL in Croatian war veterans. ${ }^{24}$ Therefore, the evaluation of personality traits seems to be important regarding the promotion of QoL in this population, and may be a risk factor for good outcomes and, therefore, deserves special attention from the health professionals who work with veterans. 
The path analysis model showed that low levels of neuroticism and post-traumatic stress symptoms predicted high levels of social support and, as a consequence, better QoL. Personality traits (eg, neuroticism) did not contribute to QoL or post-traumatic stress symptoms, but social support played a role as a mediator between neuroticism and QoL (total mediation) and between post-traumatic stress symptoms and QoL (partial mediation). According to Boscarino, ${ }^{68}$ the current level of social support is an important predictor of current mental health status and an important coping mechanism in handling stress ${ }^{44}$ what may explain how it may mediate the relationship between trauma and QoL. Since this mediation is not total, other variables play an important role in this relationship. McFarlane ${ }^{69,70}$ found neuroticism to be associated with PTSD and Dalton et $\mathrm{al}^{6}$ also found neuroticism to be an important predictor of PTSD in Vietnam veterans and these results may explain the relationship between these two variables being mediated by social support, in our sample.

According to the results, contextual variables such as social support, family functioning, and personality traits predicted some dimensions of QoL. Moreover, environmental resources such as social support mediated the relationship between personality traits such as neuroticism and posttraumatic stress symptoms and QoL, as hypothesized.

Future research should address the role of other variables, besides social support, as mediators between post-traumatic stress symptoms and QoL, particularly the role of clinical variables such as the presence of somatic complaints as well as the mediator role of post-traumatic stress symptoms between personality traits and health outcomes, besides QoL, given the negative effect of post-traumatic stress symptoms on the wives and offsprings ${ }^{71,72}$ Future studies should involve the family or the couple dyad in order to understand the systemic effect of post-traumatic stress symptoms.

According to results, it is important that mental health care professionals engage with the veteran's community in order to recognize and provide the services veterans need. One beneficial treatment strategy to explore that may increase satisfaction with social support and allows family members to be included, is support groups or counseling groups. In fact, many decades after the exposure to combat, the findings reveal that even when mental health has improved, a very high percentage is still reporting mental and physical distress including post-traumatic stress symptoms. Therefore, community resources should be explored and disseminated, in veterans' associations, church groups and day centers, where it is possible to develop and implement psychosocial intervention programs to help elderly veterans deal with the "psychological burden" they have been carrying for so many years.

This study has limitations that need to be acknowledged such as the use of a cross-sectional design that does not identify whether post-traumatic stress symptoms, psychological distress, family type or personality traits were caused by the war experience and the use of self-report instruments. In addition, veterans in this sample presented a high number of post-traumatic stress symptoms, were married and had a very low level of education. Nonetheless, this study showed that this population is in need of clinical attention. Future studies should also assess how psychological variables relate to health outcomes.

\section{Conclusion}

The elderly war veterans of the Portuguese colonial war, after so many years, present a substantial percentage of post-traumatic symptoms and this fact deserves attention of the health professionals. The results showed that psychological distress was high, the majority of the sample belonged to extreme families and personality traits (low neuroticism) and high social support contributed to post-traumatic stress symptoms and QoL, respectively, as well as age and professional status. Thus, understanding the vulnerability and risk as well as the protective factors that contribute to the development of PTSD in this population can inform the design of interventions. It is therefore important to intervene in Portuguese colonial war veterans with post-traumatic stress symptoms, not only by promoting satisfaction with social support, but taking into account also the personality, particularly in those with a neuroticism trait and are older who are at risk of having a worse psychological QoL.

\section{Data sharing statement}

Data will not be shared since they were obtained within a government assessment of Portuguese colonial wars under the implementation of the Decree-Law no. 50/2000 of April 7, which created the National Support Network.

\section{Acknowledgments}

We would like to thank the Portuguese Association of War Veterans and Hospital of Braga. This research received no specific grant from any funding agency in the public, commercial, or not-for-profit sectors.

\section{Disclosure}

The authors report no conflicts of interest in this work. 


\section{References}

1. Albuquerque A. Distúrbio Pós-Traumático de Stress em ex-combatentes da guerra colonial. [Posttraumatic Stress Disorder in Former Colonial War Veterans]. Revista de Psicologia Militar. 1992:399-407.

2. Maia A, McIntyre T, Pereira MG, Fernandes E. Por baixo das pústulas da Guerra: Reflexões sobre um estudo com Ex-combatentes da Guerra colonial [Underneath the War Pustules: Reflections on a Study of colonial War Veterans]. In: Gama M, eds. A Guerra Colonial. Braga: Centro de Estudos Lusíadas/Universidade do Minho; 2006.

3. Pedras S, Pereira MG. Características Sócio Demográficas e PTSD do Veterano de Guerra: Implicações para a Intervenção [Socio Demoghraphic Characteristics and PTSD in the War Veteran: Implications for Practice]. Oral presentation presented at the $2^{\circ}$ Internacional Simposium of Posttraumatic Stress, Portalegre, Portugal: 2007.

4. Costa PT, McCrae RR. Still stable after all these years: personality as a key to some issues in adulthood and old age. In: Baltes PB, Brim OG Jr, eds. Lifespan Development and Behavior. New York: Academic Press; 1980.

5. Roberts BW, Kuncel NR, Shiner R, Caspi A, Goldberg LR. The Power of Personality: The Comparative Validity of Personality Traits, Socioeconomic Status, and Cognitive Ability for Predicting Important Life Outcomes. Perspect Psychol Sci. 2007;2(4):313-345.

6. Dalton JE, Aubuchon IN, Tom A, Pederson SL, Mcfarland RE. MBTI profiles of Vietnam veterans with post-traumatic stress disorder. JPT. 1993;26:3-8.

7. Olson DH, Russell CS, Sprenkle DH. Circumplex Model: Systemic assessment and treatment of families. New York, NY: Haworth Press; 1989.

8. Gold JI, Taft CT, Keehn MG, King DW, King LA, Samper RE. PTSD Symptom Severity and Family Adjustment Among Female Vietnam Veterans. Military Psychology. 2007;19(2):71-81.

9. Miller MW, Wolf EJ, Reardon AF, et al. PTSD and conflict behavior between veterans and their intimate partners. J Anxiety Disord. 2013;27(2):240-251.

10. Pereira MG, Pedras S, Lopes C. Posttraumatic stress, psychological comorbidity, family functioning and quality of life in Portuguese War Veterans. Traumatology. 2012;18:49-58.

11. Pietrzak RH, Johnson DC, Goldstein MB, et al. Psychosocial buffers of traumatic stress, depressive symptoms, and psychosocial difficulties in veterans of Operations Enduring Freedom and Iraqi Freedom: the role of resilience, unit support, and postdeployment social support. J Affect Disord. 2010;120(1-3):188-192.

12. Schnurr PP, Lunney CA, Sengupta A. Risk factors for the development versus maintenance of posttraumatic stress disorder. J Trauma Stress. 2004;17(2):85-95.

13. Priebe S, Bogic M, Ajdukovic D, et al. Mental disorders following war in the Balkans: a study in 5 countries. Arch Gen Psychiatry. 2010;67(5): 518-528.

14. Koenen KC, Stellman SD, Sommer JF, Stellman JM. Persisting posttraumatic stress disorder symptoms and their relationship to functioning in Vietnam veterans: a 14-year follow-up. JTrauma Stress. 2008;21(1):49-57.

15. Schnurr PP, Lunney CA, Bovin MJ, Marx BP, Brian BP. Posttraumatic stress disorder and quality of life: extension of findings to veterans of the wars in Iraq and Afghanistan. Clin Psychol Rev. 2009;29(8):727-735.

16. Rapaport MH, Clary C, Fayyad R, Endicott J. Quality-of-life impairment in depressive and anxiety disorders. Am J Psychiatry. 2005;162(6):1171-1178.

17. Steel P, Schmidt J, Shultz J. Refining the relationship between personality and subjective well-being. Psychol Bull. 2008;134(1):138-161.

18. Lahey BB. Public health significance of neuroticism. Am Psychol. 2009;64(4):241-256.

19. Mchugh JE, Lawlor BA. Social support differentially moderates the impact of neuroticism and extraversion on mental wellbeing among community-dwelling older adults. J Ment Health. 2012;21(5): $448-458$.
20. Panayiotou G, Karekla M. Perceived social support helps, but does not buffer the negative impact of anxiety disorders on quality of life and perceived stress. Soc Psychiatry Psychiatr Epidemiol. 2013;48(2):283-294.

21. Busuttil W: Presentations and management of post traumatic stress disorder. Int J Geriatr Psychiatry. 2004;19:429-439.

22. Owens GP, Baker DG, Kasckow J, Ciesla JA, Mohamed S. Review of assessment and treatment of PTSD among elderly American armed forces veterans. Int J Geriatr Psychiatry. 2005;20(12):1118-1130.

23. Markowitz JD. Post-traumatic stress disorder in an elderly combat veteran: a case report. Mil Med. 2007;172(6):659-662.

24. Anticevic V, Kardum G, Britivic D. War Veterans? Quality of Life: The impact of lifetime traumatic experiences, psychological and physical health-related characteristics. Drustvena Istrazivanja. 2010;20.

25. McIntyre T. Escala de avaliação da resposta ao acontecimento traumático. [Post-Traumatic Stress Scale]. In: Almeida L et al. Avaliação Psicológica: Formas e contextos. 1997:37-44.

26. Derogatis LR. SCL-90: Administration, scoring and procedures manual. Baltimore MD: Clinical Psychometric Research; 1993.

27. Olson DH, Portner J, Lavee Y. FACES LY III, Family Science. University of Minnesota, 290 MnNeal Hall, Minnesota: St. Paul; 1985.

28. Pais-Ribeiro JL. Escala de Satisfação com o Suporte Social (ESSS). [Satisfaction with Social Support Scale]. Análise Psicológica. 1999;3:547-558.

29. Eysenck HJ, Eysenck SBG. Manual of the Eysenck Personality Questionnaire. San Diego, C.A: Educational and Industrial Testing Service; 1975.

30. World Health Organization Quality of Life (WHOQOL- Brief). Development of the World Health Organization WHOQOL-BREF quality of life assessment. The WHOQOL Group. Psychol Med. 1998;28:551-558.

31. Ikin JF, Creamer MC, Sim MR, Mckenzie DP. Comorbidity of PTSD and depression in Korean War veterans: prevalence, predictors, and impairment. J Affect Disord. 2010;125(1-3):279-286.

32. Kramer TL, Booth BM, Han X, Williams DK. Service utilization and outcomes in medically ill veterans with posttraumatic stress and depressive disorders. J Trauma Stress. 2003;16(3):211-219.

33. Klarić M, Frančišković T, Petrov B. P02-477 - Posttraumatic stress disorder and and concomitant comorbidity in BIH war veterans 12 years after war. European Psychiatry. 2011;26:1073-1933.

34. Iversen AC, Fear NT, Ehlers A, et al. Risk factors for post-traumatic stress disorder among UK Armed Forces personnel. Psychol Med. 2008;38(4):511-522.

35. Rona RJ, Hooper R, Jones M, et al. The contribution of prior psychological symptoms and combat exposure to post Iraq deployment mental health in the UK military. J Trauma Stress. 2009;22(1):11-19.

36. Magruder KM, Frueh BC, Knapp RG, et al. PTSD symptoms, demographic characteristics, and functional status among veterans treated in VA primary care clinics. J Trauma Stress. 2004;17(4):293-301.

37. Williams JM, Barnhofer T, Crane C, et al. Autobiographical memory specificity and emotional disorder. Psychol Bull. 2007;133(1):122-148.

38. Wright BK, Kelsall HL, Sim MR, Clarke DM, Creamer MC. Support mechanisms and vulnerabilities in relation to PTSD in veterans of the Gulf War, Iraq War, and Afghanistan deployments: a systematic review. J Trauma Stress. 2013;26(3):310-318.

39. James LM, van Kampen E, Miller RD, Engdahl BE. Risk and protective factors associated with symptoms of post-traumatic stress, depression, and alcohol misuse in OEF/OIF veterans. Mil Med. 2013;178(2):159-165

40. McCrae RR, Costa PT. The five-factor theory of personality. Handbook of personality: Theory and research. John OP, Robins RW, Pervin LA, editors. New York: Guilford Press; 2008:159-181.

41. Ogle CM, Siegler IC, Beckham JC, Rubin DC. Neuroticism increases PTSD symptom severity by amplifying the emotionality, rehearsal, and centrality of trauma memories. J Pers. 2017;85(5):702-715.

42. Caspi A, Roberts BW, Shiner RL. Personality development: stability and change. Annu Rev Psychol. 2005;56:453-484. 
43. Brewin CR, Andrews B, Valentine JD. Meta-analysis of risk factors for posttraumatic stress disorder in trauma-exposed adults. J Consult Clin Psychol. 2000;68(5):748-766.

44. Resick PA. Stress and trauma. Philadelphia PA: Taylor \& Francis Inc; 2001.

45. Ghaffarzadegan N, Ebrahimvandi A, Jalali MS. A dynamic model of post-traumatic stress disorder for military personnel and veterans. PLoS One. 2016;11(10): 0161405.

46. Monk JK, Ogolsky BG, Bruner V. Veteran couples integrative intensive retreat model: An intervention for military veterans and their relational partners. J Couple Relatsh Ther. 2016;15(2):158-176.

47. Stecker T, Fortney JC, Sherbourne CD. An intervention to increase mental health treatment engagement among OIF Veterans: a pilot trial. Mil Med. 2011;176(6):613-619.

48. Resick PA, Monson CM, Chard KM. Cognitive processing therapy: Veteran/military version: Therapist and patient materials manual. Washington, DC: Department of Veterans Affairs; 2014. Available from: https://www.div12.org/wp-content/uploads/2015/07/CPT-MaterialsManual.pdf. Accessed June 05, 2018.

49. Foa EB, Hembree E, Rothbaum BO. Prolonged exposure therapy for PTSD: Emotional processing of traumatic experiences (Therapist guide). New York: Oxford University Press; 2007.

50. Monson CM, Schnurr PP, Resick PA, Friedman MJ, Young-Xu Y, Stevens SP. Cognitive processing therapy for veterans with military-related posttraumatic stress disorder. J Consult Clin Psychol. 2006;74(5): 898-907.

51. Tuerk PW, Yoder M, Grubaugh A, Myrick H, Hamner M, Acierno R. Prolonged exposure therapy for combat-related posttraumatic stress disorder: an examination of treatment effectiveness for veterans of the wars in Afghanistan and Iraq. J Anxiety Disord. 2011;25(3): $397-403$.

52. Rutt BT, Oehlert ME, Krieshok TS, Lichtenberg JW. Effectiveness of cognitive processing therapy and prolonged exposure in the department of veterans affairs. Psychol Rep. 2018;121(2):282-302.

53. Walter KH, Varkovitzky RL, Owens GP, Lewis J, Chard KM. Cognitive processing therapy for veterans with posttraumatic stress disorder: a comparison between outpatient and residential treatment. J Consult Clin Psychol. 2014;82(4):551-561.

54. Jakupcak M, Roberts LJ, Martell C, et al. A pilot study of behavioral activation for veterans with posttraumatic stress disorder. J Trauma Stress. 2006;19(3):387-391.

55. Silver SM, Rogers S, Russell M. Eye movement desensitization and reprocessing (EMDR) in the treatment of war veterans. J Clin Psychol. 2008;64(8):947-957.

56. Krupnick JL, Melnikoff E, Reinhard M. A pilot study of interpersonal psychotherapy for PTSD in women veterans. Psychiatry. 2016;79(1):56-69.

57. Ray RD, Webster R. Group interpersonal psychotherapy for veterans with posttraumatic stress disorder: a pilot study. Int J Group Psychother. 2010;60(1):131-140.
58. Kelly MM, Sido H, Forsyth JP, Ziedonis DM, Kalman D, Cooney JL. Acceptance and commitment therapy smoking cessation treatment for veterans with posttraumatic stress disorder: a pilot study. J Dual Diagn. 2015;11(1):50-55.

59. Goodman M, Banthin D, Blair NJ, et al. A Randomized Trial of Dialectical Behavior Therapy in High-Risk Suicidal Veterans. J Clin Psychiatry. 2016;77(12):e1591-e1600.

60. Meyers L, Voller EK, Mccallum EB, et al. Treating Veterans With PTSD and Borderline Personality Symptoms in a 12-Week Intensive Outpatient Setting: Findings From a Pilot Program. J Trauma Stress. 2017;30(2):178-181.

61. Scheiderer E, Carlile JA, Aosved AC, Barlow A. Concurrent dialectical behavior therapy and prolonged exposure reduces symptoms and improves overall quality of life for a veteran with posttraumatic stress disorder and borderline personality disorder. Clin Case Stud. 2017;16(3):216-233.

62. King AP, Erickson TM, Giardino ND, et al. A pilot study of group mindfulness-based cognitive therapy (MBCT) for combat veterans with posttraumatic stress disorder (PTSD). Depress Anxiety. 2013;30(7):638-645.

63. Vujanovic AA, Niles B, Pietrefesa A, Schmertz SK, Potter CM. Mindfulness in the treatment of posttraumatic stress disorder among military veterans. Prof Psychol. 2011;42(1):24-31.

64. Martz E, Bodner T, Livneh H. Social support and coping as moderators of perceived disability and posttraumatic stress levels among Vietnam theater veterans. Health. 2010;02(04):332-341.

65. Yazicioğlu K, Duyan V, Karataş K, et al. Effects of sociodemographic characteristics, illness process, and social support on the levels of perceived quality of life in veterans. Mil Med. 2006;171(11):1083-1088.

66. Diário Digital. Estudo: Portugueses têm das pensões mais baixas da Europa [Study: Portugueses are amongst those with lowest pensions in Europe]. Lusa; 2015.

67. Miller MW. Personality and the Etiology and Expression of PTSD: A Three-Factor Model Perspective. Clin Psychol. 2003;10(4):373-393.

68. Boscarino JA. Post-traumatic stress and associated disorders among Vietnam veterans: the significance of combat exposure and social support. J Trauma Stress. 1995;8(2):317-336.

69. McFarlane AC. The aetiology of post-traumatic stress disorders following a natural disaster. Br J Psychiatry. 1988;152:116-121.

70. McFarlane AC. The longitudinal course of posttraumatic morbidity. The range of outcomes and their predictors. J Nerv Ment Dis. 1988;176(1):30-39.

71. Figley C. Burnout as systematic traumatic stress: A model for helping traumatized family members. In: Figley C, eds. Burnout in Families: The systemic costs of caring. Boca Raton: CRC Press; 1998.

72. Pereira MG, Pedras S. Vitimização Secundária nos Filhos Adultos de Veteranos da Guerra Colonial Portuguesa [Secondary Victimization in Adults Offsprings of Veterans of the Portuguese Colonial War]. Psychology. 2012;25(1):702-709.
Patient Related Outcome Measures

\section{Publish your work in this journal}

Patient Related Outcome Measures is an international, peer-reviewed, open access journal focusing on treatment outcomes specifically relevant to patients. All aspects of patient care are addressed within the journal and practitioners from all disciplines are invited to submit their work as well as healthcare researchers and patient support groups.
Dovepress

The journal is included in PubMed. The manuscript management system is completely online and includes a very quick and fair peer-review system. Visit http://www.dovepress.com/testimonials.php to read real quotes from published authors. 